\title{
REVISTAMARACANAN
}

\section{A controversa trajetória de Diogo Inácio de Pina Manique, Intendente-Geral da Polícia da Corte e do Reino. Entrevista com a Profa. Laurinda Abreu (Universidade de Évora)}

\author{
The controversial trajectory of Diogo Inácio de Pina Manique, Chief of Police \\ of the Court and Kingdom. Interview with Professor Laurinda Abreu (Évora \\ University)
}

\section{Entrevista}

Thiago Enes*

Universidade Federal Fluminense

Niterói, Rio de Janeiro, Brasil

Recebido em: 08 maio 2020.

Aprovado em: 19 jun. 2020.

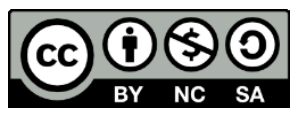

Entrevista realizada por e-mail, fruto do "Seminário de História Económica", organizado no Instituto Superior de Economia e Gestão da Universidade de Lisboa, em 3 de março de 2020.

Agradeço ao apoio do Conselho Nacional de Desenvolcimento Científico e Tecnológico - CNPq e da Coordenação de Aperfeiçoamento de Pessoal de Nível Superior - CAPES para a consecução desta entrevista.

* Doutorando no Programa de Pós-graduação em História da Universidade Federal Fluminense, com estágio doutoral no Instituto de Ciências Sociais da Universidade de Lisboa. Mestre em História pela Universidade Federal Fluminense; Bacharel e Licenciado em História pela Universidade Federal de Viçosa. (enes.thiago@gmail.com)

(iD) https://orcid.org/0000-0002-9245-6536

(9) http://lattes.cnpq.br/0081141771738701 
Lisbonne a un intendant de police qui s'est rendu aussi fameux par ses coups d'autorité, que redoutable par ses fureurs. Le non de Pina Manique imprime une terreur générale; on ose à peine le prononcer. On

n'accoste cet intendant qu'en tremblant; on se sent comme repousser par une maine invisible; l'idée de ce qu'on doit craindre de sa sévérité, toujours précipitée, en impose aux plus hardis. Son abord n'est rien moins

que rassurant: une sérieux glacé, un regard sinistre, une figure brune, sombre, rude, farouche, repousante, impriment une nouvelle terreur. ${ }^{1}$

As palavras pouco amistosas são de Joseph-Barthélemy-François Carrère, médico francês que teria entrado clandestinamente em Portugal e passado cerca de seis meses aterrorizado com o receio de ser expulso do reino por Diogo Inácio de Pina Manique (17331805), então intendente-geral da polícia, o que acabaria por acontecer quando houve maior controle dos franceses que viviam ou viajavam por Portugal após a execução do rei Luis XVI e a proclamação da Primeira República francesa, em setembro de 1792. Embora a imagem que Carrère transmite de Portugal e dos portugueses seja ostensivamente negativa, ele parecia não figurar sozinho no rechaço ao intendente Pina Manique, que é tido como um dos mais polêmicos personagens do luso império em fins do século XVIII.

Tido como homem inflexível, pelos tempos das reformas de D. Jose I, foi nomeado como superintendente dos contrabandos e descaminhos e ainda como contador da Fazenda Real por Sebastião de Carvalho e Melo, futuro Marques de Pombal. Diligente na tarefa de repressão das ilegalidades e perseguição aos infratores, conta-se que em 1777 foi encarregado de lidar com agitações surgidas na antiga freguesia de Trafaria, Concelho de Almada, reagindo com violência e passando ordens de incendiar as casas dos pobres pescadores à margem Sul do Tejo, recolhendo os mesmos amotinados às tarefas de reconstrução de Lisboa, que ainda se arrastavam após o sismo que destruiu a cidade em $1755 .^{2}$

Tal como o próprio Pombal, Diogo Inácio de Pina Manique foi figura destacada do governo português (especialmente sem seus movimentos de centralização), sendo digna de nota a sua permanência nas funções administrativas após a ascensão de D. Maria I ao trono de

\footnotetext{
1 "Lisboa tem um intendente de polícia que se tornou tão famoso pelos seus abusos de autoridade como temido pelos seus furores. O nome Pina Manique suscita um terror geral. Mal o ousam pronunciar. Não se aborda o Intendente senão tremendo, sentimo-nos como que expulsos por uma mão invisível. O medo da sua severidade, sempre excessiva, sempre irreflectida, precipitada, impõe-se até os mais corajosos. 0 seu aspecto não é mais tranqüilizador: uma expressão fria, um olhar sinistro, uma figura sombria, rude, intratável, hostil, inspiram um novo terror". CARRERE, Joseph-Barthélemy-François. Tableau de Lisbonne, en 1796; suivi de lettres écrites de Portugal sur l'état ancien et actuel de ce royaume. Paris: Jansen, 1797, p. 117. Traduação nossa.

${ }^{2}$ NORTON, José. Pina Manique: Fundador da Casa Pia. Lisboa: Bertrand, 2004, p. 21.
} 
Portugal, período que ficou popularmente conhecido como "viradeira". ${ }^{3}$ Vivendo intensamente a chamada "era das revoluções", Pina Maquine foi contemporâneo da destituição dos Bourbon na França e assistiu ao nascimento do ideário liberal e iluminista. Em oposição, tornou-se reconhecido como implacável perseguidor daqueles que, entusiasmados pelas doutrinas francesas, pretendiam introduzi-las em Portugal. Defensor da monarquia, há quem diga que à frente da Intendência Geral da Polícia, Pina Manique se mostrou um reformador com mãos de ferro, perseguiu, prendeu e deportou opositores do governo e proibiu a circulação de publicações contrárias aos seus interesses.

Figura 01 - Diogo Ignacio de Pina Manique, Intendente Geral da Polic.

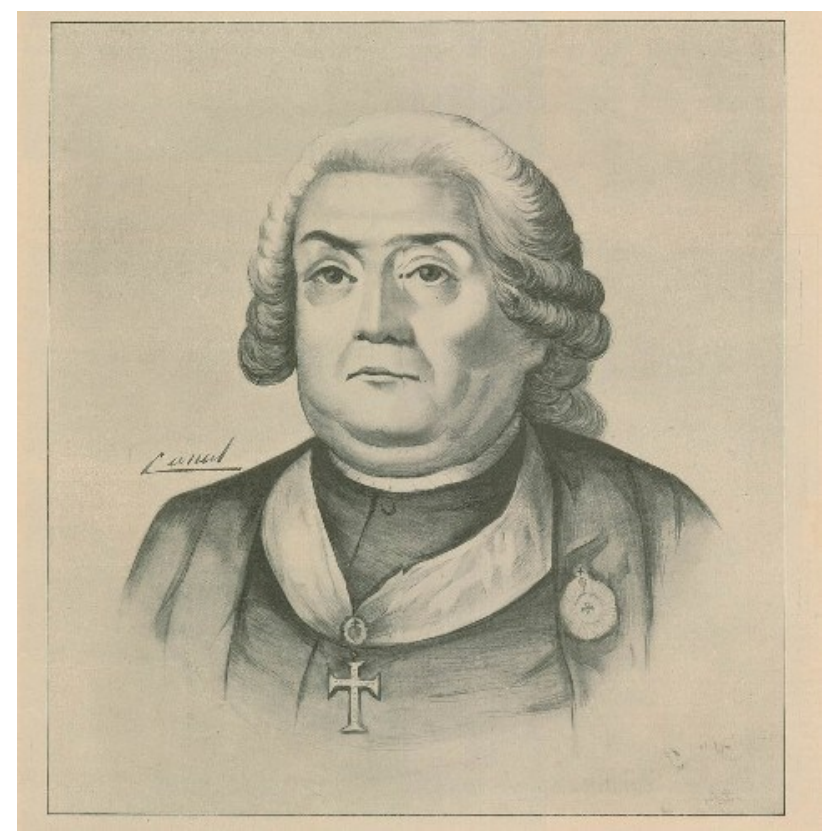

Fonte: QUEIRÓs, Gregório Francisco de (gravação); SEQUEIRA, Domingos (desenho). Diogo Ignacio de Pina Manique, Intendente Geral da Polic. 1797. Gravura em aguaforte. Biblioteca Nacional de Portugal.

Curiosamente, ao mesmo tempo em que parecia ostentar "feroz insensibilidade, quase desumana" - algo que, segundo interpretações, lhe pintava o retrato de um "ser violento, intransigente, tirano e prepotente" ${ }^{4}$ - Pina Manique também teria sido capaz de criar um programa de governo que buscava atender às necessidades dos menos favorecidos, com

\footnotetext{
${ }^{3}$ Muito embora essa interpretação seja bastante discutida e, mais recentemente, questionada pela historiografia, tradicionalmente dá-se o nome de "viradeira" ao período de reação ao governo pombalino iniciado após a aclamação de D. Maria I ao trono em 1777. Grosso modo, além da nomeação de novos secretários de governo, reabilitando parte da nobreza preterida como forma de compensação aos que se sentiram lesados pelas reformas pombalinas, houve um movimento de reaproximação da Coroa com a Igreja, a restauração das audiências reais e uma série de alterações econômicas, como a extinção de alguns dos monopólios comerciais estabelecidos por Pombal. Também foram revogadas uma série de prisões consideradas arbitrárias pelos críticos de sua condução política. Contudo, muito embora a rainha tenha nomeado novos funcionários, manteve nos cargos alguns apoiadores e até amigos do Marques de Pombal que Ihe pareceram eficientes e merecedores de confiança.

${ }^{4}$ PEREIRA, Gonçalo Magalhães Barbosa. O palácio de Manique do Intendente: proposta de requalificação. 2017. Dissertação (Mestrado em Arquitetura) - Departamento de Arquitetura da Faculdade de Ciências e Tecnologia da Universidade de Coimbra, Coimbra, p. 23.
} 
atitudes de bem ao próximo. Mais fortemente ligado à Igreja do que a Pombal, instou reformar algumas das posturas da instituição religiosa em relação à assistência em Portugal. Em 1780, fundou a Real Casa Pia de Lisboa (ainda hoje em funcionamento), obra que haveria de imortalizá-lo. Destinada à caridade e ao acolhimento dos pobres e órfãos desamparados, a Casa Pia também foi uma importante instituição de ensino e recuperação social dos afeitos às condutas desviantes, servindo aos seus ambiciosos propósitos de transformação social de Portugal. Afinal, a trajetória política e as ações de Pina Manique enquanto intendente-geral da polícia podem ser consideradas paradoxais?

Como parte integrante do dossiê "Poderes, Trajetórias e Administração no Império Português (séculos XVI-XVIII)", brindamos os leitores e leitoras da Revista Maracanan com uma entrevista com Laurinda Abreu, professora do Departamento de História da Universidade de Évora, e investigadora do CIDEHUS - Centro Interdisciplinar de História, Culturas e Sociedades, em Portugal. Mestre e Doutora em História Moderna pela Universidade de Coimbra, há mais de trinta anos a pesquisadora tem se dedicado ao estudo da assistência, da saúde e das epidemias, e de personagens e grupos sociais que, ainda nos dias atuais - talvez pela própria dificuldade de acesso à documentação oficial - são pouco referenciados pelos historiadores.

Mais recentemente, num curto espaço de tempo, Laurinda Abreu lançou dois livros, Pina Manique: um reformador no Portugal das Luzes (2013) e, apenas um ano depois, O poder e os pobres: as dinâmicas políticas e sociais da pobreza e da assistência em Portugal (séculos XVIXVIII), (2014), ambos publicados pela Editora Gradiva. Em realidade, estas duas obras parecem se reunir numa só, sendo fundamental contribuição ao entendimento do Antigo Regime lusitano, descortinando não apenas os mecanismos de assistência social voltados à proteção dos desvalidos, mas também sobre os audaciosos projetos políticos e de controle social desse intrigante personagem que foi Diogo Inácio de Pina Manique. Ainda que pouco estudado no Brasil, a sua influência como intendente atravessou o Atlântico e moldarou o funcionamento de sua congênere além-mar, a Intendência Geral de Polícia da Corte e do Estado do Brasil no Rio de Janeiro elevado a caput regni em 1808.

Thiago Enes: Antes de falarmos especificamente sobre Diogo Inácio de Pina Manique e o seu legado para a administração portuguesa, eu gostaria que a senhora nos contasse qual foi o seu percurso de investigação no campo das políticas assistenciais, da caridade e da promoção da saúde que a fez chegar até as ações desse personagem. Como foi o seu encontro com Pina Manique?

Laurinda Abreu: O meu encontro com o intendente-geral da Polícia Diogo Inácio de Pina Manique foi casual: ocorreu no início de 2011, durante a redação do livro $O$ poder e os pobres..., uma obra centrada nas questões ligadas à assistência e à pobreza na época moderna. Era meu objetivo sistematizar a investigação que tinha realizado até ali, refletindo o trabalho e as aprendizagens que tinha feito na última década no contexto de duas realidades 
distintas mas complementares: por um lado, a possibilidade de utilizar na análise histórica bases de dados de dimensões consideráveis, construídas a partir de projetos financiados pela Fundação para a Ciência e a Tecnologia, que me permitiam, por exemplo, cruzar os registos paroquiais com registos de instituições assistenciais; por outro lado, o contacto com as metodologias de trabalho e abordagens mais ligadas à área da saúde que me tinha sido proporcionado pelo grupo de trabalho que me acolheu em 2001, no âmbito da coordenação de projetos europeus e programas de formação pós-graduada, de mestrado e de doutoramento (programas Erasmus Mundus - Phoenix - Dynamics of Health and Welfare). Foi quando me preparava para redigir a última parte do referido livro que, ao entrar nos arquivos da Intendência-Geral da Polícia, encontrei um plano verdadeiramente reformador quanto às práticas assistenciais e políticas de saúde pública. E o que estava para ser um capítulo de 30 páginas rapidamente ganhou vida própria e acabou por se transformar num outro livro (Pina Manique: um reformador no Portugal das Luzes), o primeiro publicado, em 2013.

\section{Sabe-se que Diogo Inácio de Pina Manique logrou erigir uma extensa e reconhecida carreira, tendo ocupado vários cargos administrativos antes de aceder como intendente-geral. Parte da historiografia afirma que, de fato, ele foi o braço direito de Sebastião José de Carvalho e Melo nos seus intentos de construção de um novo e reformado Portugal. Quais foram as principais etapas da sua trajetória política que o teriam alçado à Intendência?}

Não obstante as várias obras escritas sobre Pina Manique (e eu convido à leitura da breve resenha que sobre elas foi feita por Patrícia Félix ${ }^{5}$ ), aguarda-se, ainda, uma biografia que analise a sua vida e obra sem qualquer viés ideológico e/ou apologético. Pessoalmente, não estudei a trajetória profissional de Pina Manique, mas é bem conhecido, como refere, que ocupou vários cargos de elevado prestígio antes de chegar à Intendência-Geral da Polícia. De entre eles, saliento: o de Desembargador da Relação e Casa do Porto; Desembargador Extravagante da Casa da Suplicação; Desembargador dos Agravos da Casa da Suplicação; Fiscal da Junta de Administração da Companhia Geral de Comércio de Pernambuco e Paraíba. É de supor que o conhecimento que tinha do sistema judicial português, aliado à experiência adquirida como juiz do crime do Castelo de S. Jorge e corregedor de Alfama, funções exercidas após a conclusão do curso de leis, na Universidade de Coimbra, Ihe tivessem dado capital social e permitido construir redes de influência que Ihe terão facilitado o acesso à intendência, em 1780.

\footnotetext{
${ }^{5}$ FÉLIX, Patrícia. Diogo Inácio de Pina Manique, Intendant Général de la Police de la Cour et du Royaume de Portugal (1780-1805): Pouvoir et actions face à la criminalité. 1998. Dissertation (Master in History) Université de Marne La Vallée, Paris.
} 
Às vésperas da aclamação da rainha D. Maria I ao trono, o marquês de Pombal era rechaçado por grande parte da população do reino e sua popularidade andava em baixa, apesar dos seus reconhecidos esforços de reconstrução de Lisboa após o terremoto de 1755. Na sua opinião, como é possível entender a sobrevivência política de Pina Manique após a saída de Pombal?

Como é sabido, houve membros do governo de Pombal que transitaram para o de D. Maria I. Pina Manique nem sequer tinha exercido funções governativas, no sentido ministerial do termo. O episódio que o liga tão negativamente a Sebastião José de Carvalho e Melo e que, em boa parte, consolida a afirmação de que seria o seu homem de confiança - o incêndio que destruiu um conjunto de barracas na Trafaria, onde estariam escondidos desertores, ciganos, vagabundos, entre outros, acusados de vários crimes -, não só carece de fundamentação documental (pelo menos, ainda não foi encontrada até ao momento), como teria ocorrido na noite de 23 para 24 de janeiro de 1777, um mês antes da morte de D. José I (a 24 de fevereiro de 1777) e sequente afastamento do marquês de Pombal. Isto para dizer que, se, de facto, aquele ato foi perpetrado a mando de Pina Manique, por ordem do marquês, era um evento relativamente recente, não só em termos de memória social, como de sustentação da ligação entre os dois homens. Seja como for, apenas no século XIX o evento da Trafaria terá entrado no imaginário popular através da biografia do marquês de Pombal elaborada por Camilo Castelo Branco, que, como bem sabemos, não era propriamente um dos seus admiradores. Foi também nesta centúria que foi construída a representação da Casa Pia (instituição ligada ao intendente, como mencionou) como um espaço de reclusão de mendigos e vagabundos, dando, assim, maior ênfase ao caso da Trafaria e omitindo que essa função foi concomitante com a formação profissional e a escolarização dos filhos dos pobres, entre muitas outras valências.

Para concluir, e, repito, sem ter feito quaisquer estudos sobre esta matéria, não me parece que o desembargador da Casa da Suplicação, Diogo Inácio de Pina Manique, sofresse danos de maior relevância na sua reputação em janeiro de 1780 , quando foi nomeado intendente-geral da Polícia.

Eu sei que essa é uma questão complexa, e que demandaria mais tempo, mas gostaria que a senhora aclarasse para nossos leitores e leitoras, em linhas gerais, sobre o contexto de surgimento da Intendência-Geral da Polícia e dessa espécie de "Estado policial" que ganhou força ao longo do século XVIII. Quais eram as características gerais dessa instituição?

A sua questão é, de facto, complexa e é abundante a bibliografia especializada que trata os conceitos e sua evolução, assim como o quadro legal e jurídico que formatou o dito "Estado de Polícia", um tópico especialmente caro a José Subtil. Segundo este, e outros 
autores, "Estado de Polícia" é o estado que se terá instalado em Portugal depois do Terramoto de 1755, um estado que corporaliza uma nova ordem política, melhor, um novo paradigma político-administrativo, que se propõe submeter o governo do país aos princípios do "interesse público" e da "felicidade das populações", princípios enunciados pela denominada "ciência de polícia".

Nos assuntos que aqui nos interessam, e para abreviar, tomo de empréstimo uma síntese de Vincent Milliot, um dos historiadores que melhor conhecem a literatura e a jurisprudência acerca do "estado de polícia", bem como a sua prática quotidiana no século XVIII, especialmente no caso francês: o autor afirma que polícia, "ciência da administração geral do estado", no sentido cameralista do termo, tinha como objetivo regular a vida em sociedade, o que incluía a manutenção da ordem moral e pública e a mobilização das populações a favor do desenvolvimento do país e, por conseguinte, do aumento do poder do Estado. Temos, assim, uma instituição eclética, dotada de um conjunto alargado de competências repressivas, como o controlo da vagabundagem, mendicidade, prostituição e infrações económicas, mas também de espionagem de atividades consideradas subversivas. Contudo, ocupava-se também da saúde pública e do bem-estar da população, atuando no sentido de aumentar o número e a duração das vidas úteis.

No caso português, a Intendência-Geral da Polícia foi criada pelo diploma de 25 de junho de 1760, no contexto da nova "administração de tipo intendencial" (José Subtil). Todavia, o que efetivamente surgiu nesse ano de 1760 foi uma entidade que centralizava num único organismo várias funções de controlo social que andavam dispersas por diferentes entidades e magistrados, de modo a tornar esse controlo mais eficaz. Sei que existe algum simplismo nesta afirmação, porém basta analisar a atividade da Intendência-Geral da Polícia até aos finais de 1779 para verificar que ela não está muito longe da realidade. A situação alterou-se em 1780, quando, na minha perspetiva, se deu uma refundação da instituição. $O$ processo foi preparado com algum cuidado, como explico no meu livro, permitindo-me dele distinguir dois momentos: o da publicação do diploma de 15 de janeiro de 1780 (três dias antes da nomeação de Pina Manique como intendente) referente ao "pequeno crime", cuja punição passava "por alguma correção", concedendo autoridade ao intendente-geral da Polícia para gerir os tempos do cárcere; e o estabelecimento da Casa Pia de Lisboa, em maio do mesmo ano, uma instituição que permitia à Intendência-Geral da Polícia atuar nos vários campos sociais. Na prática, estamos em presença de duas instituições preparadas para funcionarem em articulação, complementando-se: a Intendência-Geral da Polícia fornecia à Casa Pia capacidade de ação e meios disciplinares; a Casa Pia operacionalizava o programa formativo, reformador e de reinserção social mas também sanitarista e de desenvolvimento da saúde pública.

A partir de então, em Portugal, a polícia passou efetivamente a seguir os ensinamentos divulgados pelo Traité de la Police de Paris, de Nicolas Delamare, publicado em 1710, princípios expandidos e desenvolvidos na obra de Johann Heinrich Gottlob von Justi, Grundsätze der Policey-Wissenschaft, de 1756. Tenho fundadas razões para crer que Pina 
Manique conhecia bem esta última obra e que foi a partir da versão francesa, publicada em 1769, e nesse verão enviada para Lisboa por Ribeiro Sanches, que começou a atuar; antes, portanto, da tradução (da versão espanhola) de João Rosado Villalobos, publicada em Portugal sob o título Elementos Gerais da Policia de um Estado, entre 1786-87. Obra que Villalobos dedica a Pina Manique, referindo-se a ela como se a temática fosse estranha ao intendente.

Da leitura de suas obras é possível apreender que a senhora acredita que Pina Manique dispunha de um projeto político e de uma agenda de reformas para soerguer um novo Portugal econômica e socialmente. Ao mesmo tempo, a senhora afirma que se debruçar sobre a biografia de Pina Manique é testemunhar uma utopia, que teria durado cerca de três anos. Por que é que seus projetos se transformaram numa utopia? A senhora afirma ainda que, num dado momento, ele próprio toma consciência da impossibilidade de concretização dos seus planos. Por que isso ocorre?

Não estou completamente certa se foi assumido como um projeto político. Porém, dos milhares de documentos analisados para a elaboração do meu livro (apenas uma pequena parte da documentação produzida pela Intendência-Geral da Polícia entre 1780 e 1805), ficou claro para mim que Pina Manique tinha uma visão sobre o que deveria ser o país, quer do ponto de vista social, quer económico. A matriz era, como referi, enxertada em Delamare e von Justi, a de polícia enquanto ciência da política e administração pública, cujo objetivo era aumentar a riqueza e o poder do Estado. Um programa que teve várias componentes e que foi estruturado em três linhas principais: o fomento agrícola, manufatureiro e industrial (a Intendência participou no esforço de reforma económica e social do reino, um assunto que ainda não explorei em profundidade, no entanto, penso fazê-lo); a saúde pública; a educação e a formação profissional.

Passada a primeira metade de 1780, todas estas vertentes estavam a ser implementadas pela Intendência-Geral da Polícia e pela Casa Pia, ainda que em diferentes níveis, num complexo jogo de escalas que previa a sua replicação em todo o país. Era um trabalho suportado na recolha e acumulação de informação que permitia, por exemplo, elaborar estatísticas de mortalidade e morbilidade.

Detenhamo-nos, apenas, nas políticas sociais e de saúde pública. Como tenho defendido, Pina Manique terá sido o primeiro governante a formalizar em Portugal um pensamento já há algum tempo difundido noutros países europeus: o principal problema de saúde pública era a pobreza. É nesta ótica que se explica o alargado programa (que, nalguns casos, não passou de um plano) de prestação de cuidados médicos gratuitos às populações mais pobres; a aposta na formação de agentes de saúde; as políticas de desenvolvimento sanitário, para combater as doenças infecciosas e prevenir as epidemias, tanto as importadas como as que se desenvolviam internamente em resultado da falta de higiene e de condições sanitárias; o investimento em novas técnicas para evitar mortes ou enterrar pessoas vivas; a 
tentativa de proibir os enterros nas igrejas; a participação nas experiências da inoculação e vacinação da varíola ou, até, a condução de testes para uso de uma nova quina. Em suma, a ideia de que a saúde era um fator importante para o desenvolvimento económico e riqueza dos estados, considerando-a um investimento estatal que compensava, por se refletir na produção e consumo. Simultaneamente, na Casa Pia, através da escolarização, da formação académica e do ensino profissional, sobretudo dos jovens e das mulheres, criavam-se condições para permitir que os filhos dos pobres fossem autossuficientes e, assim, escapassem à delinquência, quebrando o ciclo da reprodução da pobreza.

Todo este programa convocava um enorme esforço económico. Atente-se que, em 1781 (um ano depois de ter sido inaugurada), a Casa Pia contava já com 1400 residentes, espalhados pela Casa da Força (uma espécie de reformatório) e por diversos colégios, diferenciados segundo o público-alvo: desde as crianças que ali aprendiam as primeiras letras às órfãs, que estavam a ser preparadas para o serviço doméstico ou manufatureiro; mas também as prostitutas, em processo de reconversão social. Como será demonstrado em duas teses de doutoramento que estou a orientar (teses de Christelle de Monserrate e de Maria Luísa Gama), a institucionalização no Castelo de São Jorge, onde funcionava a Casa Pia, era tendencialmente curta, tendo a maioria dos homens e mulheres sido reintegrada na comunidade de origem e/ou na família.

Tudo isto tinha custos elevadíssimos, como disse, e logo em 1782 Pina Manique se via na contingência de alterar os seus planos por falta de recursos financeiros, uma condição que se agravou a partir de então. Vários indícios na documentação consultada apontam para que essa situação tivesse sido intencional, razão pela qual eu falo numa utopia, que rapidamente se esboroou: o medo de um poder que se espraiava por diversos sectores e os permanentes conflitos jurisdicionais protagonizados pelo intendente terão provocado a rápida perda de apoio político e esta manifestou-se, entre outras formas, no corte do financiamento à Casa Pia e na sua progressiva transformação numa instituição muito diferente daquela que tinha sido planeada por Pina Manique.

\section{Há uma discussão historiográfica um tanto quanto acalorada (mas ao mesmo tempo muito interessante) sobre Pina Manique e os meios tidos como pouco ortodoxos de atingir os seus objetivos políticos. Afinal, como a senhora o percebe? Ele pode ser considerado um déspota, ou devemos observar 0 conjunto e o impacto de suas obras, apesar do seu caráter considerado ríspido?}

Quando menciona objetivos políticos, reporta-se ao seu programa de trabalho, no sentido da questão anterior, creio. Vejamos, Pina Manique era o chefe de uma instituição que tinha entre os seus propósitos garantir a segurança do país em todas as vertentes em que esta pudesse ser ameaçada. Para cumprir esse desígnio, o alvará fundador da Intendência-Geral da Polícia, de 25 de junho de 1760, havia concedido ao intendente-geral da Polícia jurisdição 
ilimitada sobre todos os ministros criminais e civis e demais agentes periféricos da coroa e magistraturas locais. Poderes reforçados em 1801 pela Guarda Real da Polícia, um corpo que Pina Manique já vinha a requerer desde 1789. Acrescem a isso os "poderes ilimitados" que D. Maria I Ihe terá concedido, segundo o próprio um alvará de lei secreto, cujo conteúdo desconhecemos por completo, datado de 15 de junho de 1780.

Recordemos que Pina Manique era intendente de um governo absolutista, que apoiava incondicionalmente, num momento em que essa forma de governo estava a ser questionada na Europa e até fisicamente ameaçada. Esperar que atuasse de um modo diferente comporta alguns riscos em termos da análise histórica. Esclareça-se, contudo, que esta minha afirmação não tem subjacente qualquer juízo valorativo da atividade de Pina Manique. O que defendo é precisamente o contrário: a necessidade de enquadrar o personagem no seu tempo histórico e analisar a sua ação nas suas múltiplas vertentes.

Com certeza que havia opiniões divergentes, ao tempo, em Portugal, algumas delas profundamente contrárias à atuação do intendente. A começar por todos os que por ele foram visados e que sentiram ameaçados os seus interesses, direitos e privilégios, desde os ministros régios às instituições, aos grupos económicos e às corporações. Ou, ainda, as magistraturas periféricas, por exemplo, obrigadas a produzir trabalho e a obedecer, sob ameaça de despedimento e, várias vezes, de voz de prisão. Em síntese, o olhar retrospetivo não pode ser anacrónico, fracionado ou valorativo. O que não impede de observar que boa parte dos conflitos que alimentou decorreu da sua recusa em aceitar a conceção jurisdicional vigente que implica o respeito por outros poderes. Sabemos bem que as sociedades de Antigo Regime se sustentam em equilíbrios de poder; nesse sentido falta-nos, por exemplo, uma análise muito fina à correlação de forças no governo de D. Maria I. Contudo, esse não é o meu campo de trabalho.

Para nós que nos dedicamos à história política, é quase óbvio que pesquisar sobre a administração é, por extensão, investigar os personagens que estiveram a cargo dessa administração, afinal, as instituições e suas funções foram e são, ainda, moldadas e pautadas pelas ações dos seus executores. Nesse sentido, eu creio que entre os brasileiros seja possível falar num conhecimento mais ou menos consolidado sobre a atuação da IntendênciaGeral de Polícia da Corte e do Estado do Brasil, sobretudo em seus primeiros anos, sob a tutela de Paulo Fernandes Viana. A senhora acha que a atuação de Pina Manique em Portugal e em Lisboa pode ter influenciado a Intendência no Brasil? Por que, apesar de alguns dos seus projetos terem sido frustrados, essa instituição foi levada ao Brasil com a importante missão de ordenar a sociedade após a elevação do Rio de Janeiro à condição de corte real?

A transposição de instituições do reino para o Brasil não é um assunto que tenha estudado mas, tanto quanto sei, os diplomas que criaram a Intendência-Geral da Polícia da 
Corte e do Estado do Brasil e o cargo de intendente, respetivamente em 5 de abril e 10 de maio de 1808, apontam nesse sentido. Neste segundo documento, lesse que cumpria os alvarás de 25 de junho de 1760 e o de 15 de janeiro de 1780, não só no respeitante à jurisdição que tinha o Intendente-Geral da Polícia em Portugal como até em relação ao seu ordenado (que se manteve em 1:600\$000). Também seguem essa orientação os estudos realizados por colegas brasileiros, mormente os que se reportam ao primeiro intendente, o desembargador Paulo Fernandes Viana, e que contam sobre os múltiplos problemas que teve de enfrentar, desde a gestão administrativa à angariação de receitas, aos conflitos com outras instituições. Um cenário muito idêntico ao que Pina Manique tinha encontrado em 1780, isto, bem entendido, tendo em conta os diferentes contextos e realidades sociais, nomeadamente 0 fenómeno da escravatura, no que tange a Fernandes Viana. Mas também reações a um modo de atuação com bastantes similitudes.

Igualmente formado em Direito na Universidade de Coimbra, e tendo ocupado alguns cargos em Portugal durante o governo de Pina Manique na Intendência-Geral da Polícia, é muito provável que Fernandes Viana conhecesse bem o seu modo de atuação e tivesse sido por ele influenciado. De resto, à parte a dita diferença de escalas e de contextos, o relatório de atividades que Fernandes Viana elaborou quando teve de abandonar o cargo - Abreviada demonstração dos trabalhos de Polícia em todo o tempo que a serviu o desembargador do Paço Paulo Fernandes Viana de 5 de abril de 1808 a 26 de fevereiro de 1821 - tem muitos pontos de contacto com o produzido por Pina Manique em 26 de junho de 1799 "para que de futuro não venha eu ou meus herdeiros a sofrer algumas incomodidades que emperigue a minha memória". Uma das muitas razões que justifica, creio, uma análise comparativa entre a Intendência-Geral da Polícia e a atuação de Pina Manique e a Intendência-Geral da Polícia da Corte e do Estado do Brasil e o governo de Fernandes Viana. 


\section{Referências}

ABREU, Laurinda. O poder e os pobres: as dinâmicas políticas e sociais da pobreza e da assistência em Portugal (séculos XVI-XVIII). Lisboa: Gradiva, 2014.

ABREU, Laurinda. Pina Manique: um reformador no Portugal das Luzes. Lisboa: Gradiva, 2013.

CARRÈRE, Joseph-Barthélemy-François. Tableau de Lisbonne, en 1796; suivi de lettres écrites de Portugal sur l'état ancien et actuel de ce royaume. Paris: Jansen, 1797.

FÉLIX, Patrícia. Diogo Inácio de Pina Manique, Intendant Général de la Police de la Cour et du Royaume de Portugal (1780-1805): Pouvoir et actions face à la criminalité. 1998. Dissertation (Master in History) - Université de Marne La Vallée, Paris.

NORTON, José. Pina Manique: Fundador da Casa Pia. Lisboa: Bertrand, 2004.

PEREIRA, Gonçalo Magalhães Barbosa. O palácio de Manique do Intendente: proposta de requalificação. 2017. Dissertação (Mestrado em Arquitetura) - Departamento de Arquitetura da Faculdade de Ciências e Tecnologia da Universidade de Coimbra, Coimbra. 